\title{
Annual dynamics of the plasma sex steroid hormones of the Malaysian Walking Catfish Clarias batrachus (Linnaeus 1758)
}

\begin{abstract}
Malaysia is one of the countries in Asia with higher scarcity of Clarias batrachus. Consequently, to arrive at better ways of handling the situation the reproductive endocrinology of the species was investigated. Testosterone (T), 11-ketotestosterone (11KT) and $17 \beta$-estradiol $\left(\mathrm{E}_{2}\right)$ were the plasma sex steroid hormones monitored monthly throughout the reproductive cycles. Several peak levels were observed in the annual profiles of all the steroid hormones, implying that $C$. batrachus is a non-seasonal breeder, signifying that the species could spawn several times during the reproductive cycle. Most of the scholars who earlier worked on the breeding of this fish concentrated on a particular period (May to August) assuming that was the only season successful induced breeding of the species could be achieved. The present study has enhanced the understanding of the reproduction of $C$. batrachus. It has provided a platform for the optimization of reproduction and breeding program of the species.
\end{abstract}

Keyword: Clarias batrachus; Reproductive cycle; Plasma sex steroid hormones 